\title{
Similarity Analysis for Effects of Variable Diffusivity and Heat Generation/Absorption on Heat and Mass Transfer for a MHD Stagnation-Point Flow of a Convective Viscoelastic Fluid over a Stretching Sheet with a Slip Velocity
}

\author{
H. M. El-Hawary, ${ }^{1}$ Mostafa A. A. Mahmoud, ${ }^{2}$ \\ Reda G. Abdel-Rahman, ${ }^{2}$ and Abeer S. Elfeshawey ${ }^{2}$ \\ ${ }^{1}$ Department of Mathematics, Faculty of Science, Assiut University, Assiut 71516, Egypt \\ ${ }^{2}$ Department of Mathematics, Faculty of Science, Benha University, Benha 13518, Egypt \\ Correspondence should be addressed to Abeer S. Elfeshawey; abeer_elfeshawey@yahoo.com
}

Received 14 October 2012; Revised 17 February 2013; Accepted 7 April 2013

Academic Editor: Bozidar Sarler

Copyright (C) 2013 H. M. El-Hawary et al. This is an open access article distributed under the Creative Commons Attribution License, which permits unrestricted use, distribution, and reproduction in any medium, provided the original work is properly cited.

A mathematical analysis has been carried out for stagnation-point heat and mass transfer of a viscoelastic fluid over a stretching sheet with surface slip velocity, concentration dependent diffusivity, thermal convective boundary conditions, and heat source/sink. The governing partial differential equations are reduced to a system of nonlinear ordinary differential equations using Lie group analysis. Numerical solutions of the resulting ordinary differential equations are obtained using shooting method. The influences of various parameters on velocity, temperature, and mass profiles have been studied. Also, the effects of various parameters on the local skin-friction coefficient, the local Nusselt number, and the local Sherwood number are given in graphics form and discussed.

\section{Introduction}

Practical applications have demand to find the solution of differential equations governing the motion of non-Newtonian fluids. Several types of non-Newtonian fluids exist, but one of the public ones is the viscoelastic fluid; they can exhibit a response that resembles that of an elastic solid under some circumstances or the response of a viscous liquid under other circumstances. In nature, fluids that exhibit this behavior are macromolecular such as polymeric fluids used to make plastic articles, food systems such as dough used to make bread and pasta, and biological fluids such as synovial fluids found in joints. Flow of a viscoelastic fluid and heat transfer phenomena over a stretching surface are encountered in a wide range of chemical and engineering applications, particularly in manufacturing process of artificial film, artificial fibers, polymer extrusion, drawing of plastic films and wires, glass fiber and paper production, manufacture of foods, and crystal growing. Rajagopal et al. [1] analyzed the flow of secondorder fluid over a stretched surface. Dandapat and Gupta
[2] extended this problem to present the exact analytical solutions of the nonlinear equations governing this problem. Vajravelu and Rollins [3] studied heat transfer characteristics in a viscoelastic fluid over a stretching sheet with frictional heating and internal heat generation/absorption.

Flow and mass transfer of a viscoelastic fluid over a stretching sheet were studied by many authors. Kelly et al. [4] investigated the analytical solution for the problem of heat and mass transfer of an MHD viscoelastic fluid over a porous stretching sheet. Sanjayanand and Khan [5] carried out the problem of heat and mass phenomena in a viscoelastic fluid flow over an exponentially stretching impermeable sheet. Cortell [6] presented the numerical analysis of flow and mass transfer for two MHD viscoelastic fluids, namely, secondgrade and second-order non-Newtonian fluids, over a porous stretching sheet. Mahmoud [7] studied the effects of variable viscosity, surface slip velocity, and chemical reaction on the flow and mass transfer of a viscoelastic fluid immersed on porous medium over a stretching surface. 


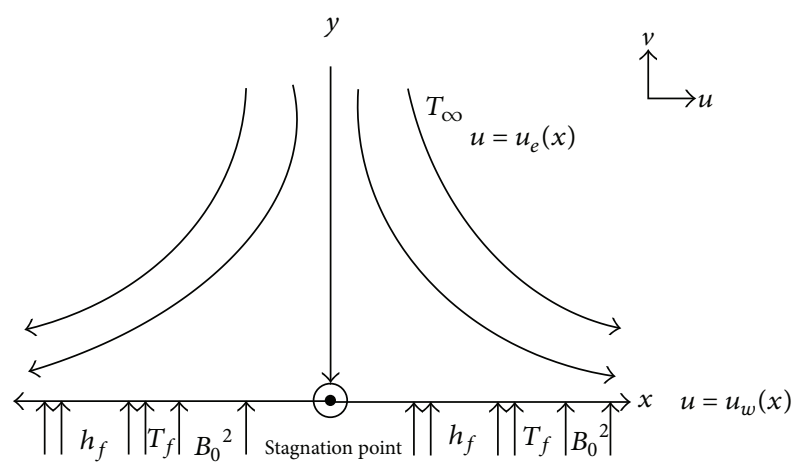

Figure 1: Physical model and the coordinate system.

Heat transfer for an electrically conducting viscoelastic fluid flow over a stretching sheet under the influence of a magnetic field in presence of heat source is considered to be of significant importance due to its application in many engineering problems such as magnetohydrodynamic (MHD) generator, plasma studies, nuclear reactors, oil exploration, geothermal energy extractions, and the boundary-layer control in the field of aerodynamics. Recently, researches in these fields have been studied by several authors. Abel et al. [8] studied the problem of heat transfer for an incompressible electrically conduction viscoelastic fluid flow over a linear stretching sheet in the presence of viscous and ohmic dissipation. Singh [9] investigated the analytical solution of the effects of uniform magnetic field, thermal radiation, and heat source on the flow and heat transfer of a viscoelastic fluid over a stretching flat plat; two types of heating processes are studied: (i) prescribed power law surface temperature (PST) and (ii) prescribed power law surface heat flux (PHT). The influence of the variable thermal conductivity on the flow of an MHD viscoelastic fluid over a stretching surface in the presence of thermal radiation, viscous dissipation, and a nonuniform heat source was carried out by Abel and Mahesha [10], they studied the problem under the two different types of boundary conditions PST and PHF boundary conditions. Hsiao [11] examined the effects of magnetic and electric dissipation on the MHD flow of a second grade fluid in the presence of heat source/sink. The analytical solution for the flow of two types of viscoelastic fluids in the presence of Joule heating and viscous dissipation and internal heat generation/absorption over a stretched surface has been found by Chen [12]. Nandeppanavar et al. [13] considered the problem of heat transfer of a MHD viscoelastic fluid over an impermeable stretching sheet with nonuniform heat source/sink.

In all the previous researches, the diffusion coefficient is taken to be constant. However, there are some problems where the diffusion coefficient varies with the concentration over a certain range. The diffusion coefficient can often be approximated by a linear or exponential dependence equation [14-16].

In recent years, the stagnation-point flow of viscoelastic fluid past a stretching surface has attracted the interest of many investigators. Mahapatra and Gupta [17] studied the laminar steady stagnation-point flow of a viscoelastic fluid over a stretching surface; they studied the flow when the stretching velocity of the surface is more (less) than the freestream velocity. Ayub et al. [18] extended the results of Mahapatra and Gupta [17]; they solved the problem analytically using HAM method. Li et al. [19] investigated the problem of steady mixed convection flow of viscoelastic fluid over a heated or cooled vertical flat plate near a stagnation point.

Lie group analysis, also called symmetry analysis, was developed by Sophius Lie to find point transformations which map a given partial differential equation to ordinary differential equation [20-25]. An extensive literature exist on this subject, and Bhuvaneswari et al. [26] examine the effect of chemical reaction on the natural convection flow and mass transfer of a steady viscous fluid past a semi-infinite inclined surface using Lie group analysis. Abd-el-Malek and Hassan [27] studied the symmetry analysis for the steady twodimensional boundary-layer stagnation-point flow of RivlinEricksen fluid of second-grade with a uniform suction. Jalil et al. [28] calculated Lie symmetries of the equations of mixed convection flow and mass transfer over a stretching surface with suction/injection. The similarity solution for the effect of generation/absorption, suction/blowing on the flow, and mass transfer of a nanofluid over a stretching sheet in a porous medium near a stagnation point is investigated by Hamad and Ferdows [29].

The aim of the present study is to find new similarity transformations with their corresponding similarity solutions and to investigate heat and mass transfer of an MHD viscoelastic fluid moving over a stretching surface near a stagnation point in the presence of slip velocity, heat source/sink, and the concentration dependent thermal diffusivity.

\section{Mathematical Formulation of the Problem}

Consider the two-dimensional steady flow of an incompressible electrically conducting viscoelastic fluid past a stretching sheet which coincides with the plane $y>0$ in the presence of heat source and a uniform magnetic field applied normal to the plate. The magnetic Reynolds number of the flow is taken to be small enough so that the induced magnetic field is assumed to be negligible. The down surface of the plate is heated by convection from a hot fluid of temperature $T_{f}$ which provides a heat transfer coefficient $h_{f}$, as shown in Figure 1. Under the boundary-layer approximations the governing equations of the continuity, momentum, energy, and concentration for the steady flow can be written as [7]

$$
\begin{gathered}
\frac{\partial \bar{u}}{\partial \bar{x}}+\frac{\partial \bar{v}}{\partial \bar{y}}=0 \\
\bar{u} \frac{\partial \bar{u}}{\partial \bar{x}}+\bar{v} \frac{\partial \bar{u}}{\partial \bar{y}} \\
=\bar{u}_{e} \frac{d \bar{u}_{e}}{d \bar{x}}+\nu \frac{\partial^{2} \bar{u}}{\partial \bar{y}^{2}} \\
-\frac{K_{0}}{\rho}\left(\frac{\partial \bar{u}}{\partial \bar{x}} \frac{\partial^{2} \bar{u}}{\partial \bar{y}^{2}}+\bar{u} \frac{\partial^{3} \bar{u}}{\partial \bar{x} \partial \bar{y}^{2}}+\frac{\partial \bar{u}}{\partial \bar{y}} \frac{\partial^{2} \bar{v}}{\partial \bar{y}^{2}}+\bar{v} \frac{\partial^{3} \bar{u}}{\partial \bar{y}^{3}}\right) \\
-\frac{\sigma B_{0}^{2}}{\rho}\left(\bar{u}-\bar{u}_{e}\right),
\end{gathered}
$$




$$
\begin{gathered}
\rho c_{p}\left(\bar{u} \frac{\partial T}{\partial \bar{x}}+\bar{v} \frac{\partial T}{\partial \bar{y}}\right)=\kappa \frac{\partial^{2} T}{\partial \bar{y}^{2}}+Q\left(T-T_{\infty}\right), \\
\bar{u} \frac{\partial C}{\partial \bar{x}}+\bar{v} \frac{\partial C}{\partial \bar{y}}=\frac{\partial}{\partial \bar{y}}\left(D(C) \frac{\partial C}{\partial \bar{y}}\right),
\end{gathered}
$$

subject to the boundary conditions

$$
\begin{gathered}
\bar{y}=0: \bar{u} \\
=\bar{u}_{w}(\bar{x})+N_{1}\left[\frac{\mu}{\rho} \frac{\partial \bar{u}}{\partial \bar{y}}-\frac{K_{0}}{\rho}\left(\bar{u} \frac{\partial^{2} \bar{u}}{\partial \bar{y} \partial \bar{x}}+2 \frac{\partial \bar{u}}{\partial \bar{x}} \frac{\partial \bar{u}}{\partial \bar{y}}\right)\right] \\
\bar{v}=0, \quad-\kappa \frac{\partial T}{\partial \bar{y}}=h_{f}\left(T_{f}-T\right), \quad C=C_{w} \\
\bar{y} \longrightarrow \infty: \bar{u}=\bar{u}_{e}(\bar{x}), \quad \frac{\partial \bar{u}}{\partial \bar{y}}=0 \\
T=T_{\infty}, \quad C=C_{\infty}
\end{gathered}
$$

Introducing the following dimensionless variables

$$
\begin{gathered}
x=\frac{\bar{x}}{L}, \quad y=\frac{\bar{y}}{L} \sqrt{\mathrm{Re}}, \quad u=\frac{\bar{u}}{U_{0}}, \\
v=\frac{\bar{v}}{U_{0}} \sqrt{\mathrm{Re}}, \quad u_{w}(x)=\frac{\bar{u}_{w}(\bar{x})}{U_{0}}, \\
u_{e}(x)=\frac{\bar{u}_{e}(\bar{x})}{U_{0}}, \quad \theta=\frac{T-T_{\infty}}{T_{f}-T_{\infty}}, \quad \varphi=\frac{C-C_{\infty}}{C_{w}-C_{\infty}},
\end{gathered}
$$

where $\operatorname{Re}=L U_{0} / \nu$ is the Reynolds number, then the dimensionless forms of (1)-(2b) are

$$
\begin{gathered}
\frac{\partial u}{\partial x}+\frac{\partial v}{\partial y}=0 \\
u \frac{\partial u}{\partial x}+v \frac{\partial u}{\partial y}=u_{e} \frac{d u_{e}}{d x}+\frac{\partial^{2} u}{\partial y^{2}} \\
-K\left(\frac{\partial u}{\partial x} \frac{\partial^{2} u}{\partial y^{2}}+u \frac{\partial^{3} u}{\partial x \partial y^{2}}+\frac{\partial u}{\partial y} \frac{\partial^{2} v}{\partial y^{2}}+v \frac{\partial^{3} u}{\partial y^{3}}\right) \\
-M\left(u-u_{e}\right), \\
u \frac{\partial \theta}{\partial x}+v \frac{\partial \theta}{\partial y}=\frac{1}{\operatorname{Pr}} \frac{\partial^{2} \theta}{\partial y^{2}}+\gamma \theta, \\
u \frac{\partial \varphi}{\partial x}+v \frac{\partial \varphi}{\partial y}=\frac{1}{\operatorname{Sc}} \frac{\partial}{\partial y}\left((1+b \varphi) \frac{\partial \varphi}{\partial y}\right) .
\end{gathered}
$$

The dimensionless boundary conditions are

$$
\begin{gathered}
y=0: u=u_{w}(x)+a\left[\frac{\partial u}{\partial y}-K\left(u \frac{\partial^{2} u}{\partial x \partial y}+2 \frac{\partial u}{\partial x} \frac{\partial u}{\partial y}\right)\right] \\
v=0, \quad \frac{\partial \theta}{\partial y}=-\beta(1-\theta), \quad \varphi=1,
\end{gathered}
$$

$$
\begin{gathered}
y \longrightarrow \infty: u=u_{e}(x), \quad \frac{\partial u}{\partial y}=0, \\
\theta=0, \quad \varphi=0,
\end{gathered}
$$

where $K=K_{0} U_{0} / \rho \nu L$ is the viscoelastic parameter, $M=$ $\sigma B_{0}^{2} L / \rho U_{0}$ is the magnetic parameter, $\operatorname{Pr}=\rho \nu c_{p} / \kappa$ is the Prandtl number, $\gamma=Q L / U_{0} \rho c_{p}$ is the heat generation $(\gamma>$ $0)$ /absorption $(\gamma<0)$ parameter, Sc $=\nu / D_{m}$ is the Schmidt number, $a=N_{1} \nu \sqrt{\mathrm{Re}} / L$ is the slip parameter, and $\beta=$ $\left(h_{f} / \kappa\right) \sqrt{L \nu / U_{0}}$ is the convective parameter. Here we assumed that the variable concentration diffusivity given by the linear relation [16]

$$
D(C)=D_{m}\left(1+c\left(C-C_{\infty}\right)\right)=D_{m}(1+b \varphi),
$$

where $c$ is a constant and $b$ is the concentration diffusivity parameter.

Introducing stream function $\psi$ as

$$
u=\frac{\partial \psi}{\partial y}, \quad v=-\frac{\partial \psi}{\partial x}
$$

then (4)-(5b) will have the form

$$
\begin{aligned}
H_{1}= & \frac{\partial \psi}{\partial y} \frac{\partial^{2} \psi}{\partial x \partial y}-\frac{\partial \psi}{\partial x} \frac{\partial^{2} \psi}{\partial y^{2}}-u_{e} \frac{d u_{e}}{d x}-\frac{\partial^{3} \psi}{\partial y^{3}} \\
& +K\left(\frac{\partial^{2} \psi}{\partial x \partial y} \frac{\partial^{3} \psi}{\partial y^{3}}+\frac{\partial^{4} \psi}{\partial x \partial y^{3}} \frac{\partial \psi}{\partial y}-\frac{\partial^{2} \psi}{\partial y^{2}} \frac{\partial^{3} \psi}{\partial x \partial y^{2}}\right. \\
& \left.-\frac{\partial \psi}{\partial x} \frac{\partial^{4} \psi}{\partial y^{4}}\right) \\
& +M\left(\frac{\partial \psi}{\partial y}-u_{e}\right)=0, \\
H_{2}= & \frac{\partial \psi}{\partial y} \frac{\partial \theta}{\partial x}-\frac{\partial \psi}{\partial x} \frac{\partial \theta}{\partial y}-\frac{1}{\operatorname{Pr}} \frac{\partial^{2} \theta}{\partial y^{2}}-\gamma \theta=0, \\
H_{3}= & \frac{\partial \psi}{\partial y} \frac{\partial \varphi}{\partial x}-\frac{\partial \psi}{\partial x} \frac{\partial \varphi}{\partial y}-\frac{1}{\mathrm{Sc}}\left(b\left(\frac{\partial \varphi}{\partial y}\right)^{2}+(1+b \varphi) \frac{\partial^{2} \varphi}{\partial y^{2}}\right) \\
= & 0 .
\end{aligned}
$$


The related boundary conditions are

$$
\begin{gathered}
y=0: \frac{\partial \psi}{\partial y} \\
=u_{w}(x)+a\left[\frac{\partial^{2} \psi}{\partial y^{2}}-K\left(\frac{\partial \psi}{\partial y} \frac{\partial^{3} \psi}{\partial x \partial y^{2}}+2 \frac{\partial^{2} \psi}{\partial x \partial y} \frac{\partial^{2} \psi}{\partial y^{2}}\right)\right], \\
\frac{\partial \psi}{\partial x}=0, \quad \frac{\partial \theta}{\partial y}=-\beta(1-\theta), \quad \varphi=1, \\
y \longrightarrow \infty: \frac{\partial \psi}{\partial y}=u_{e}(x), \quad \frac{\partial^{2} u}{\partial y^{2}}=0 \\
\theta=0, \quad \varphi=0 .
\end{gathered}
$$

\section{Symmetry Analysis}

A symmetry admitted by (8)-(10) is a transformation mapping any solution of (8)-(10) into another solution of (8)$(10)$. Consider the one-parameter $(\varepsilon)$ Lie group of infinitesimal transformations leaving (8)-(10) invariant given by

$$
\begin{gathered}
\tilde{x}=x+\varepsilon \zeta_{x}\left(x, y, \psi, \theta, \varphi, u_{e}\right)+O\left(\varepsilon^{2}\right), \\
\tilde{y}=y+\varepsilon \zeta_{y}\left(x, y, \psi, \theta, \varphi, u_{e}\right)+O\left(\varepsilon^{2}\right), \\
\tilde{\psi}=\psi+\varepsilon \eta_{\psi}\left(x, y, \psi, \theta, \varphi, u_{e}\right)+O\left(\varepsilon^{2}\right), \\
\tilde{\theta}=\theta+\varepsilon \eta_{\theta}\left(x, y, \psi, \theta, \varphi, u_{e}\right)+O\left(\varepsilon^{2}\right), \\
\tilde{\varphi}=\varphi+\varepsilon \eta_{\varphi}\left(x, y, \psi, \theta, \varphi, u_{e}\right)+O\left(\varepsilon^{2}\right), \\
\widetilde{u_{e}}=u_{e}+\varepsilon \eta_{u_{e}}\left(x, y, \psi, \theta, \varphi, u_{e}\right)+O\left(\varepsilon^{2}\right),
\end{gathered}
$$

where $\varepsilon$ is the group parameter and $\zeta_{x}, \zeta_{y}, \eta_{\psi}, \eta_{\theta}, \eta_{\varphi}$, and $\eta_{u}$ are infinitesimal elements of the group. The associated Lie algebra of infinitesimal symmetry is the set of the vector field of the form

$$
\begin{aligned}
\chi= & \sum_{i=1}^{2} \zeta_{i}\left(x, y, \psi, \theta, \varphi, u_{e}\right) \frac{\partial}{\partial x_{i}} \\
& +\sum_{\alpha=1}^{4} \eta_{\alpha}\left(x, y, \psi, \theta, \varphi, u_{e}\right) \frac{\partial}{\partial u^{\alpha}}
\end{aligned}
$$

where $u^{\alpha}=\psi, \theta, \varphi$, and $u_{e}$ for $\alpha=1, \ldots, 4$, respectively, $x_{i}=x, y$ for $i=1,2$, respectively. The action of $\chi$ is extended to all derivatives appearing in (8)-(10) through the fourth prolongation

$$
\operatorname{pr}^{(4)} \chi=\chi+\eta_{\alpha}^{[i]} \frac{\partial}{\partial u_{i}^{\alpha}}+\cdots+\eta_{\alpha}^{[i j]} \frac{\partial}{\partial u_{i j}^{\alpha}}+\cdots+\eta_{\alpha}^{[i j k l]} \frac{\partial}{\partial u_{i j k l}^{\alpha}}
$$

where

$$
\begin{gathered}
\eta_{\alpha}^{[i]}=D_{i} \eta_{\alpha}-\left(D_{i} \zeta_{\beta}\right) u_{i}^{\alpha}, \\
\eta_{\alpha}^{[i j]}=D_{j} \eta_{\alpha}^{[i]}-\left(D_{j} \zeta_{\beta}\right) u_{i \beta}^{\alpha}, \\
\eta_{\alpha}^{[i j k]}=D_{k} \eta_{\alpha}^{[i j]}-\left(D_{k} \zeta_{\beta}\right) u_{i j \beta}^{\alpha}, \\
\eta_{\alpha}^{[i j k l]}=D_{l} \eta_{\alpha}^{[i j k]}-\left(D_{l} \zeta_{\beta}\right) u_{i j k \beta}^{\alpha},
\end{gathered}
$$

where $i, j, k, l$, and $\beta=1,2, \alpha=1,2, \ldots, 4$, and $D_{i}$ is the total derivative operator defined as

$$
D_{i}=\frac{\partial}{\partial x_{i}}+u_{i}^{\alpha} \frac{\partial}{\partial u^{\alpha}}+u_{i j}^{\alpha} \frac{\partial}{\partial u_{j}^{\alpha}}+\cdots, \quad i=1,2 .
$$

The operator $\chi$ is a point symmetry of (8)-(10) if

$$
\left.\operatorname{pr}^{(4)}\left(H_{i}\right)\right|_{H_{i}=0}=0, \quad i=1,2,3 \text {, }
$$

where $H_{i}=0, i=1,2,3$, for (8)-(10). Expanding the system (17) with the aid of mathematica and setting the coefficients of like derivatives of $\psi, \theta, \phi$, and $u_{e}$ in system equal zero, one obtains an overdetermined linear system of PDEs for infinitesimal $\zeta_{x}, \zeta_{y}, \eta_{\psi}, \eta_{\theta}, \eta_{\varphi}$, and $\eta_{u_{e}}$. Solving these sets of equations, we obtain the components of symmetries as follows:

$$
\begin{aligned}
& \zeta_{x}=c_{1} x+c_{2}, \quad \zeta_{y}=c_{3}, \quad \eta_{\psi}=c_{4}+c_{1} \psi, \\
& \eta_{\theta}=c_{5} \theta, \quad \eta_{\varphi}=0, \quad \eta_{u_{e}}=c_{1} u_{e},
\end{aligned}
$$

where $c_{1}, c_{2}, c_{3}, c_{4}$, and $c_{5}$ are constants. The characteristic equation for obtaining the similarity transformation would then be

$$
\frac{d x}{c_{1} x+c_{2}}=\frac{d y}{c_{3}}=\frac{d \psi}{c_{1} \psi+c_{4}}=\frac{d \theta}{c_{5} \theta}=\frac{d \varphi}{0}=\frac{d u_{e}}{c_{1} u_{e}} .
$$

The resulting similarity variable is

$$
\eta=y-\ln \left(x+\frac{c_{2}}{c_{1}}\right)^{c_{3} / c_{1}}, \quad c_{1} \neq 0
$$

and the similarity functions are

$$
\begin{gathered}
\psi(x, y)=\left(x+\frac{c_{2}}{c_{1}}\right) f(\eta)-\frac{c_{4}}{c_{1}}, \\
\theta(x, y)=\left(x+\frac{c_{2}}{c_{1}}\right)^{c_{5} / c_{1}} \theta(\eta), \\
\varphi(x, y)=\varphi(\eta), \quad u_{e}(x)=S\left(x+\frac{c_{2}}{c_{1}}\right),
\end{gathered}
$$

where $S$ is an integration constant.

Moreover, in our problem to satisfy the boundary conditions (11), $c_{3}, c_{4}$, and $c_{5}$ must equal zero. This implies that the similarity variable (20) and similarity functions (21) are

$$
\begin{gathered}
\eta=y, \quad \psi(x, y)=(x+A) f(\eta), \quad \theta(x, y)=\theta(\eta), \\
\varphi(x, y)=\varphi(\eta), \quad u_{e}(x)=S(x+A), \\
u_{w}(x)=x+A,
\end{gathered}
$$


where $A=c_{2} / c_{1}$, which may be taken to equal zero, and $u_{w}$ is the velocity of the stretching surface. Substituting (22) into (8)-(11) we get the following system of ordinary differential equations:

$$
\begin{gathered}
f^{\prime \prime \prime}+f^{\prime \prime} f-f^{\prime 2}+K\left(f f^{\prime \prime \prime \prime}-2 f^{\prime} f^{\prime \prime \prime}+f^{\prime \prime 2}\right) \\
+M\left(s-f^{\prime}\right)+S^{2}=0 \\
\theta^{\prime \prime}+\operatorname{Pr}\left(f \theta^{\prime}+\gamma \theta\right)=0, \\
f \varphi^{\prime}+\frac{1}{\mathrm{Sc}}\left(b \varphi^{\prime}+(1+b \varphi) \varphi^{\prime \prime}\right)=0,
\end{gathered}
$$

with the corresponding boundary conditions

$$
\begin{gathered}
\eta=0: f^{\prime}=1+a f^{\prime \prime}\left(1-3 K f^{\prime}(0)\right), \\
f=0, \quad \theta^{\prime}=-\beta(1-\theta), \quad \varphi=1, \\
\eta \longrightarrow \infty: f^{\prime}=S, \quad f^{\prime \prime}=0, \quad \theta=\varphi=0,
\end{gathered}
$$

where

$$
\begin{aligned}
& \eta=y, \quad \psi(x, y)=x f(\eta), \quad \theta(x, y)=\theta(\eta), \\
& \varphi(x, y)=\varphi(\eta), \quad u_{e}(x)=S x, \quad u_{w}(x)=x .
\end{aligned}
$$

The parameter $S$ measures the ratio between the free-stream velocity to the plate velocity; that is, where $S>1$, the freestream velocity is greater than the plate velocity, and while $S<$ 1 , the free-stream velocity is smaller than the plate velocity.

The exact solution for (23), subjected to boundary conditions (26a) and (26b) can be obtained for $(S=a=0)$ [4]

$$
\begin{gathered}
f(\eta)=\frac{1-\exp ^{-\alpha \eta}}{\alpha}, \quad \alpha=\left(\frac{1+M}{1-K}\right)^{1 / 2}, \\
f^{\prime \prime}(0)=-\left(\frac{1+M}{1-K}\right)^{1 / 2} .
\end{gathered}
$$

Also, we can solve (25) analytically with $b=0$ by using the transformation

$$
\xi(\eta)=-\frac{\mathrm{Sc}}{\alpha^{2}} \exp ^{-\alpha \eta}
$$

Then (25) will be transformed to

$$
\xi \varphi^{\prime \prime}(\xi)+\varphi^{\prime}(\xi)\left(1-\xi-\frac{\mathrm{Sc}}{\alpha^{2}}\right)=0
$$

subject to boundary conditions

$$
\varphi\left(\xi=-\frac{\mathrm{Sc}}{\alpha^{2}}\right)=1, \quad \varphi(\xi=0)=0 .
$$

The exact solution to (31) satisfying the boundary conditions (32) in terms of $\eta$ is

$$
\varphi(\eta)=\frac{\Gamma\left(\mathrm{Sc} / \alpha^{2}\right)-\Gamma\left(\mathrm{Sc} / \alpha^{2},\left(\mathrm{Sc} / \alpha^{2}\right) \exp ^{-\alpha \eta}\right)}{\Gamma\left(\mathrm{Sc} / \alpha^{2}\right)-\Gamma\left(\mathrm{Sc} / \alpha^{2}, \mathrm{Sc} / \alpha^{2}\right)},
$$

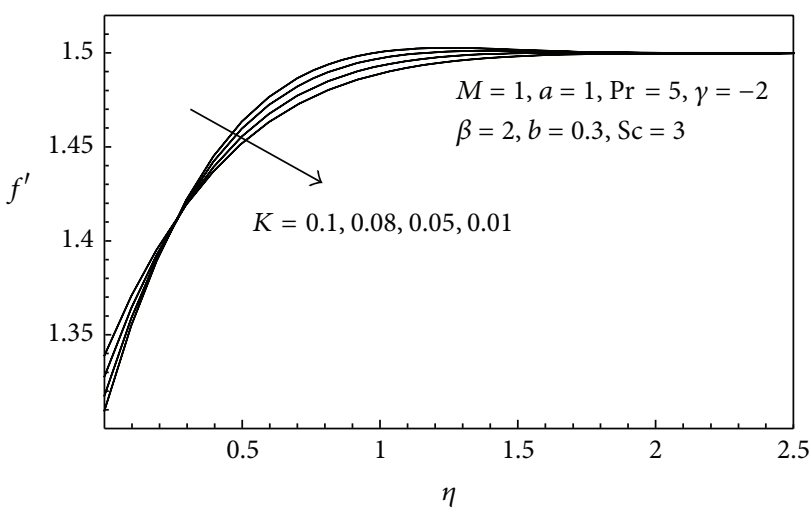

FigURE 2: Velocity profiles for various values of $K$ with $S=1.5$.

where $\Gamma(x)$ is Gamma function and $\Gamma(x, y)$ is the incomplete Gamma function. The rate of heat transfer is given as

$$
\varphi^{\prime}(\eta)=-\frac{\exp ^{-\mathrm{Sc}\left(\exp ^{-\alpha \eta} / \alpha^{2}\right)-\alpha \eta} \operatorname{Sc}\left(\operatorname{Sc}\left(\exp ^{-\alpha \eta} / \alpha^{2}\right)\right)^{\mathrm{Sc} / \alpha^{2}-1}}{\alpha\left[\Gamma\left(\mathrm{Sc} / \alpha^{2}\right)-\Gamma\left(\mathrm{Sc} / \alpha^{2}, \mathrm{Sc} / \alpha^{2}\right)\right]},
$$

$$
\varphi^{\prime}(0)=-\frac{\exp ^{-\mathrm{Sc} / \alpha^{2}} \mathrm{Sc}\left(\mathrm{Sc} / \alpha^{2}\right)^{\mathrm{Sc} / \alpha^{2}-1}}{\alpha\left[\Gamma\left(\mathrm{Sc} / \alpha^{2}\right)-\Gamma\left(\mathrm{Sc} / \alpha^{2}, \mathrm{Sc} / \alpha^{2}\right)\right]} .
$$

The physical quantities of interest are the local skinfriction coefficient $C f_{x}$, the local Nusselt number $\mathrm{Nu}_{x}$, and the local Sherwood number $\mathrm{Sh}_{x}$, which are defined, respectively, as

$$
\begin{gathered}
\frac{1}{2} C f_{x} \operatorname{Re}_{x}^{1 / 2}=-\left(1-3 K f^{\prime}(0)\right) f^{\prime \prime}(0), \\
\mathrm{Nu}_{x} \operatorname{Re}_{x}^{-1 / 2}=-\theta^{\prime}(0) \\
\mathrm{Sh}_{x} \operatorname{Re}_{x}^{-1 / 2}=-\varphi^{\prime}(0)
\end{gathered}
$$

where $\operatorname{Re}_{x}=\sqrt{\bar{x} \bar{u}_{w} / v}$ indicates the local Reynolds number.

\section{Numerical Results and Discussion}

For this present system of nonlinear differential equations (23)-(25), subject to boundary conditions (26a) and (26b), numerical computations have been carried out by fourthorder Runge-Kutta integration with the shooting scheme. In order to assess the accuracy of our results, we have compared our results for (23) and (25), subjected to boundary conditions (26a) and (26b) with the analytical solutions (29) and (35) as shown in Table 1.

The comparison shows a good agreement. Numerical results are plotted in Figures $2-16$ to exhibit the influences of the various parameters on the velocity, heat, and mass transfer with the boundary layer. The values of Sc increase from 0.1 (low weight diffusing gas species) through 0.5 (oxygen diffusing) to 1 (denser hydrocarbon derivatives as the diffusing species), 3 , and 5 for more denser species [30].

Figures 2 and 3 depict the variations in the velocity for different numerical values of viscoelastic parameter $K$ for 
TABLE 1: Comparison for the values of $-f^{\prime \prime}(0)$ and $-\varphi^{\prime}(0)$ with $\mathrm{Sc}=0.5$.

\begin{tabular}{|c|c|c|c|c|c|}
\hline \multirow{2}{*}{$K$} & \multirow{2}{*}{$M$} & \multicolumn{2}{|c|}{$-f^{\prime \prime}(0)$} & \multicolumn{2}{|c|}{$-\varphi^{\prime}(0)$} \\
\hline & & Analytical solution & Present study & Analytical solution & Present study \\
\hline 0.1 & 0 & 1.05409 & 1.05409 & 0.344825 & 0.344828 \\
\hline 0.2 & 0 & 1.1803 & 1.1803 & 0.33387 & 0.333875 \\
\hline 0.3 & 0 & 1.19523 & 1.19523 & 0.321235 & 0.321237 \\
\hline 0.4 & 0 & 1.29099 & 1.29099 & 0.306453 & 0.306455 \\
\hline 0.1 & 0.5 & 1.29099 & 1.29099 & 0.306453 & 0.306455 \\
\hline 0.2 & 0.5 & 1.36931 & 1.36931 & 0.295082 & 0.295086 \\
\hline 0.3 & 0.5 & 1.46385 & 1.46385 & 0.282177 & 0.2821773 \\
\hline 0.4 & 0.5 & 1.58114 & 1.58114 & 0.267353 & 0.267357 \\
\hline
\end{tabular}

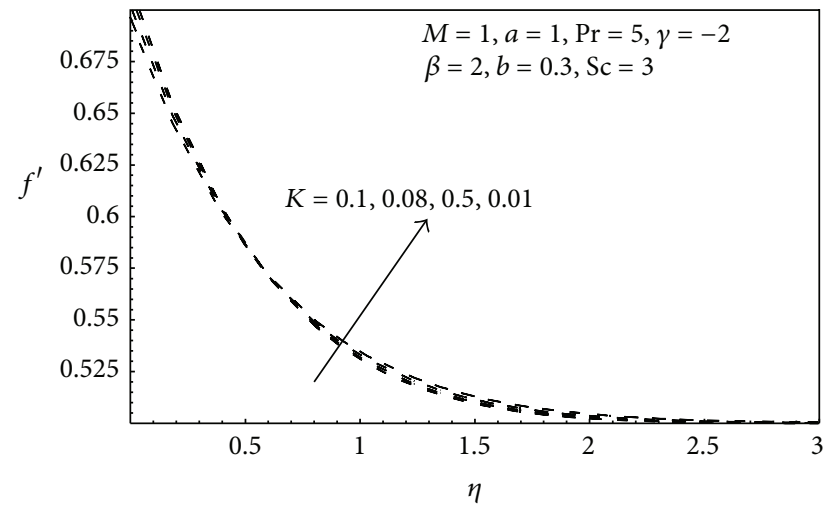

FIGURE 3: Velocity profiles for various values of $K$ with $S=0.5$.

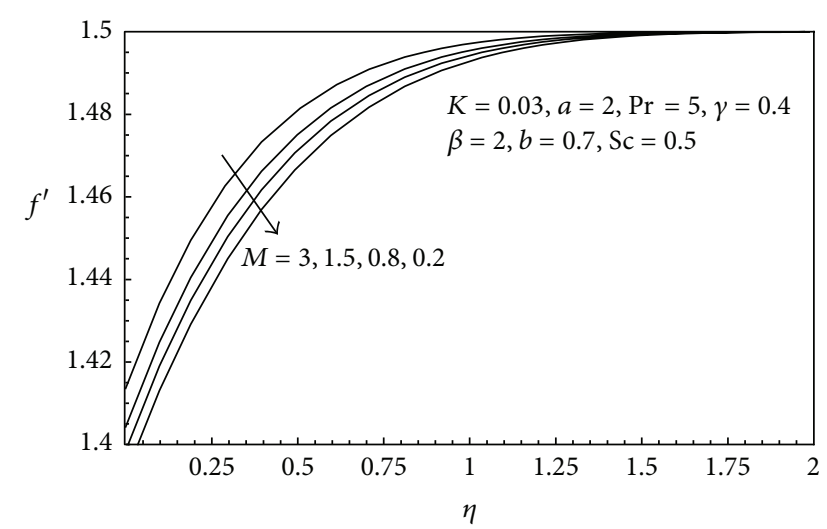

FIGURE 4: Velocity profiles for various values of $M$ with $S=1.5$.

$S=1.5$ and $S=0.5$, respectively. From Figure 2 it can be notice that the velocity $f^{\prime}$ decreases with an increase in $K$ near the surface, and the reverse is true away from the surface. It was observed from Figure 3 that velocity $f^{\prime}$ increases with an increase in $K$ near the surface, and the reverse is true away from the surface.

Figures 4 and 5 show the velocity distribution for various values of the magnetic field $M$. From Figure 4 we can notice that for $S=1.5$ an increase in the value of magnetic parameter $M$ leads to an increase in the velocity profile within the boundary layer. But Figure 5 depicts that increasing $M$

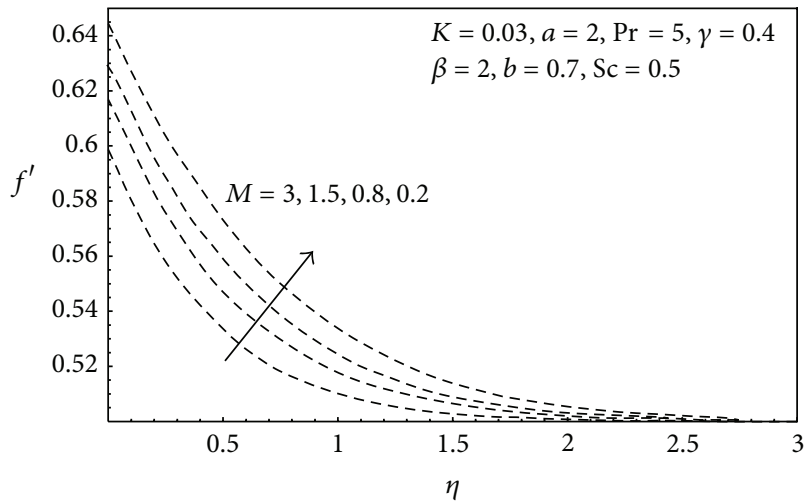

FIGURE 5: Velocity profiles for various values of $M$ with $S=0.5$.

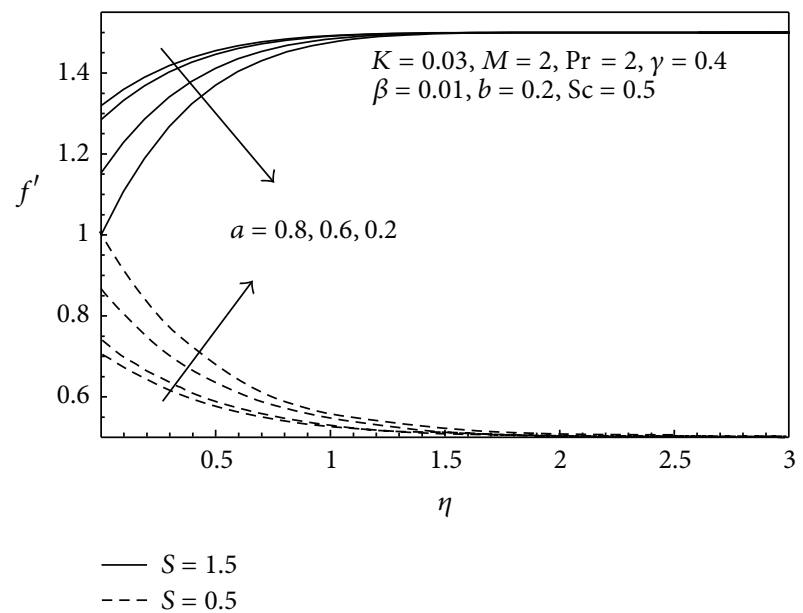

FIGURE 6: Velocity profiles for various values of $a$.

decreases the velocity $f$; this is because the application of a transverse magnetic field to an electrically conducting fluid gives rise to a resistive-type force called the Lorentz force. This force has the tendency to slow down the motion of the fluid in the boundary layer.

Figures 6, 7, and 8 illustrate the influence of slip velocity parameter on the velocity and temperature profiles with $S=$ 0.5 and 1.5 , respectively. It shows that slip parameter increases the velocity $f^{\prime}$ for $S=1.5$ and decreases for $S=0.5$ and vice versa with respect to the temperature $\theta$. 


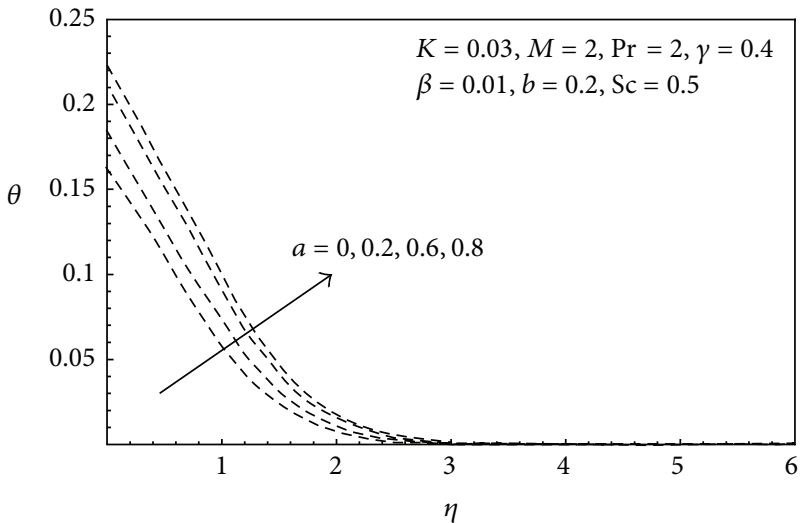

FIgURE 7: Temperature profiles for various values of $a$ with $S=0.5$.

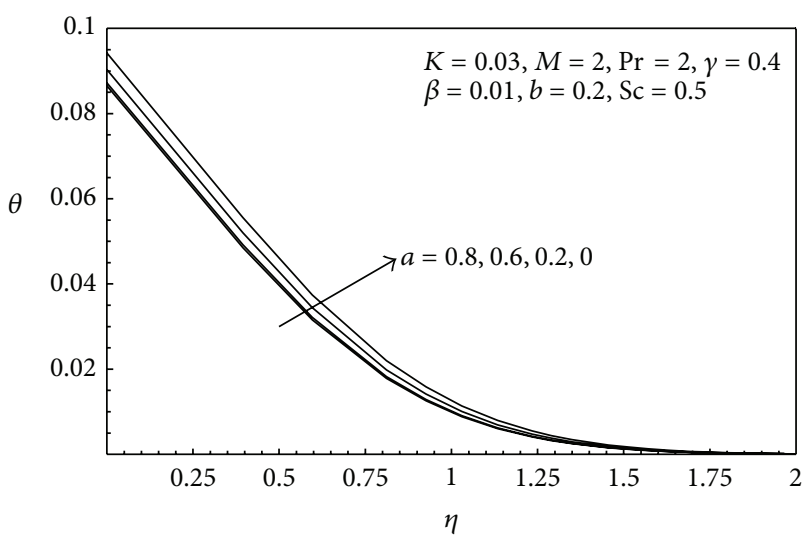

FIgURE 8: Temperature profiles for various values of $a$ with $S=1.5$.

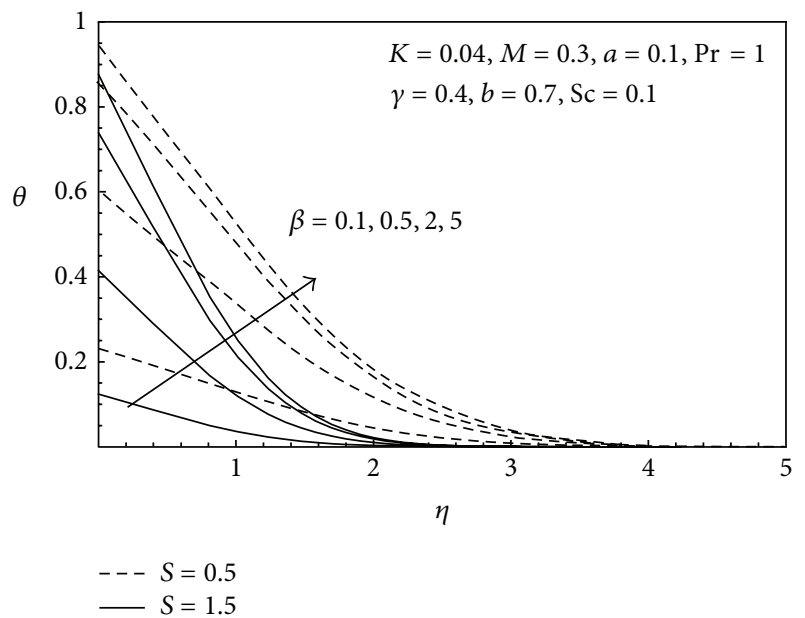

FIGURE 9: Temperature profiles for various values of $\beta$.

Figure 9 shows the temperature profile for different values of the convective parameter $\beta$; one can find that the temperature profiles and their corresponding thicknesses of the boundary layer increase as $\beta$ increases.

Figure 10 illustrates the effect of $b$ on the concentration gradient; one can observe that the concentration gradient decreases when $b$ increases for both $S=0.5$ and $S=1.5$.

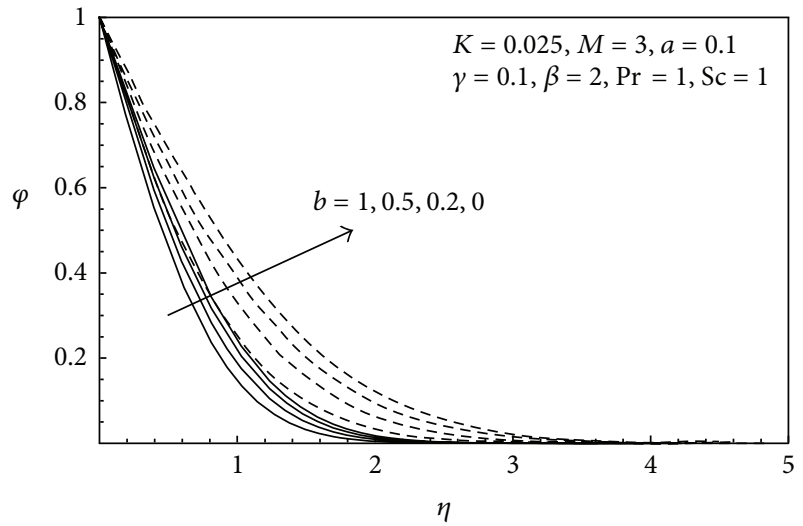

$---S=0.5$

$-S=1.5$

FIGURE 10: Mass profiles for various values of $b$.

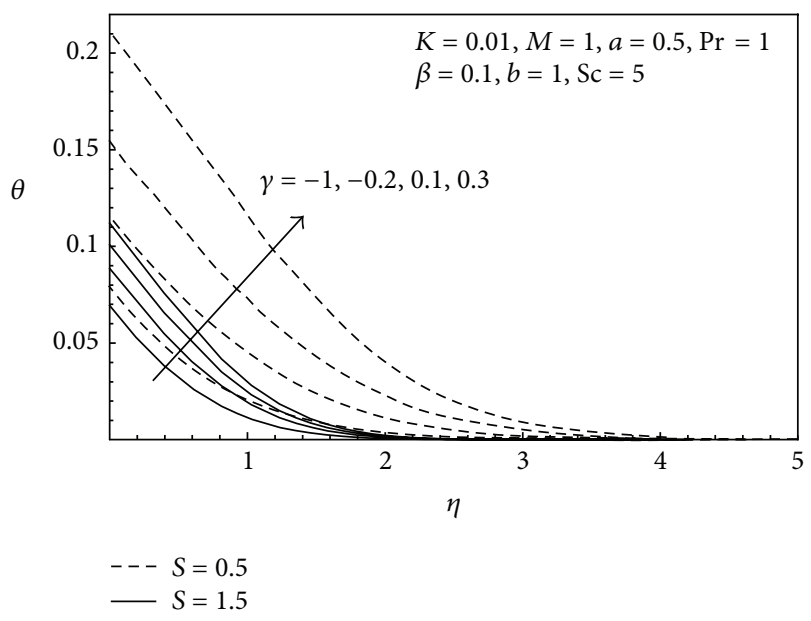

FIGURE 11: Temperature profiles for various values of $\gamma$.

Figure 11 presents typical profiles for the temperature for various values of a heat source $(\gamma>0)$ or a heat sink $(\gamma<0)$, respectively. As shown, the temperature is increasing with increasing heat source, but it decreases with increasing heat sink. In all cases, the magnitude of $\gamma$ effect causes an increasing in the thermal boundary-layer thickness.

Figure 12 illustrates the variation of the temperature profiles $\theta$ over a range of Prandtl number Pr. It is noticed that the temperature is decreasing as $\mathrm{Pr}$ increases. The influence Prandtl number Pr on the thickness of the thermal boundary layer is according to the well-known relation $\delta_{\theta} / \delta \approx \operatorname{Pr}^{-1 / 2}$, where $\delta_{\theta}$ is the thickness of the thermal boundary layer and $\delta$ is the thickness of the velocity boundary layer. So, the thickness of the thermal boundary layer increases as Pr decreases, and hence the temperature $\theta$ increases with the decrease of $\mathrm{Pr}$.

Figure 13 presents the behavior of the concentration profile for the variation of Schmidt number Sc; it is seen that the decrease in the values of Sc increases the concentration. 


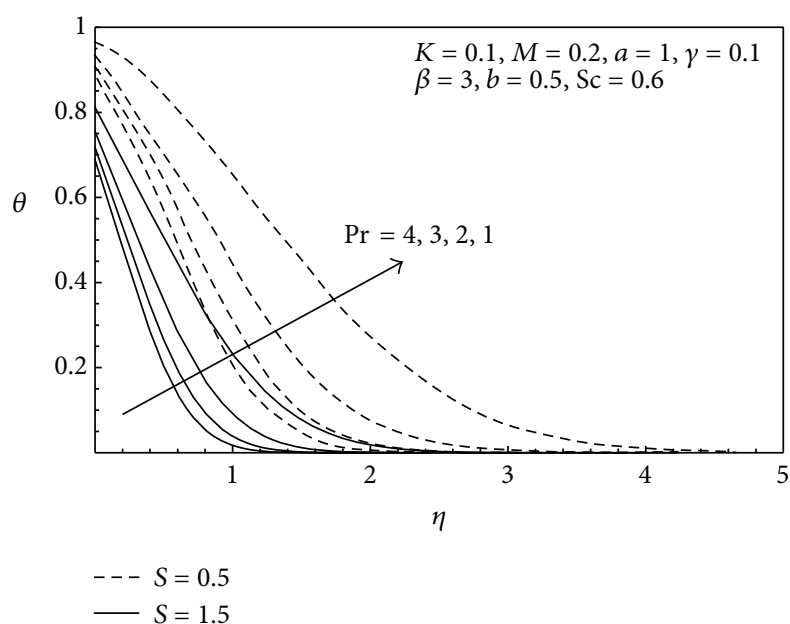

FIGURE 12: Temperature profiles for various values of $\mathrm{Pr}$.

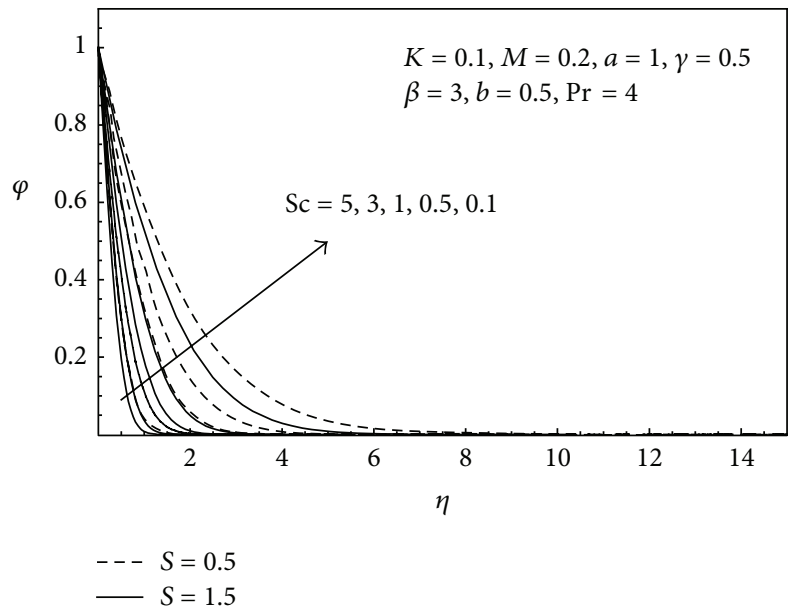

Figure 13: Mass profiles for various values of Sc.

Figures 14, 15, and 16 display the effect of the parameter $S$ on the velocity, temperature, and concentration, respectively. It is clear that the velocity increases as the parameter $S$ increases, but the temperature and the concentration decrease by increasing $S$.

Figure 17 describes the effect of the viscoelastic parameter $K$ and the magnetic parameter $M$ on local skin-friction coefficient for two cases $S=1.5$ and $S=0.5$ keeping all other parameters fixed. It is noticed that as $K$ increases, the local skin-friction coefficient decreases for $S=1.5$ and $S=0.5$. Also, it is observed that for a fixed value of $K$ the local skinfriction coefficient increases with increasing $M$ for $S=1.5$ and $S=0.5$.

The variations of the local Nusselt number with $a$ for various values of $\beta$ for two cases $S=0.5$, and 1.5 when all other parameters fixed are shown in Figure 18. It is found that the local Nusselt number increases with increasing $a$ for $S=1.5$ while it decreases for $S=0.5$ with fixed value of $\beta$. Also, the local Nusselt number increases with increasing $\beta$ for $S=1.5$ and $S=0.5$ at a fixed value of $a$.

Figure 19 shows the parameters $\gamma$ and Pr effects on the local Nusselt number. It is observed that the local Nusselt

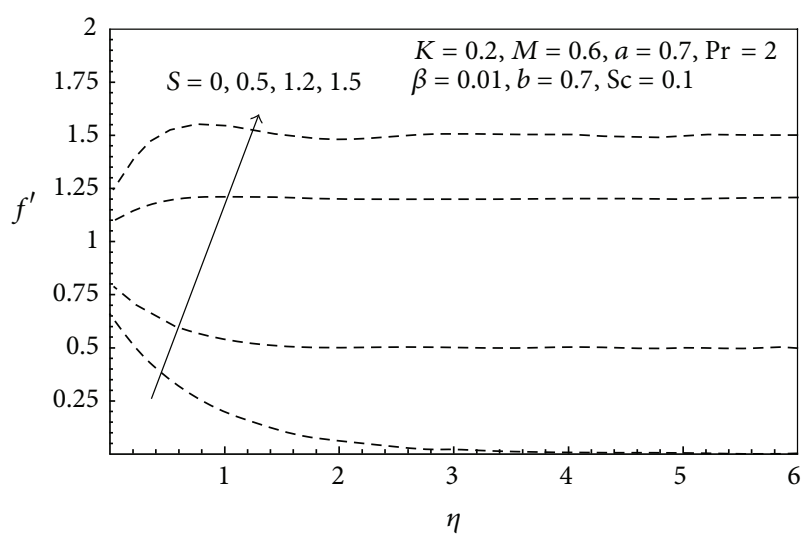

FIGURE 14: Velocity profiles for various values of $S$.

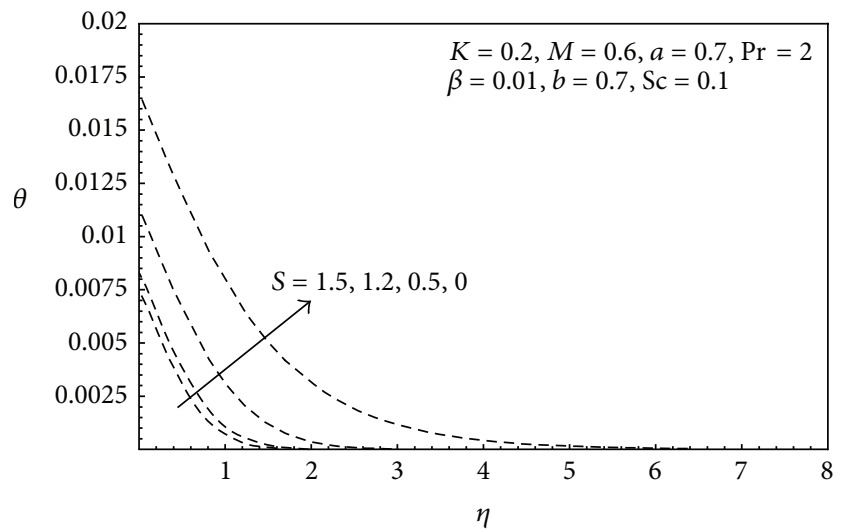

Figure 15: Temperature profiles for various values of $S$.

number decreases with the parameter $\gamma$ increasing for $S=0.5$ and $S=1.5$ for a fixed value of $\operatorname{Pr}$. However, it increases by increasing $\operatorname{Pr}$ at a fixed value of $\gamma$ and for $S=0.5$ and $S=1.5$.

The influence of the parameters $b, \mathrm{Sc}$ on the local Sherwood number has been described in Figure 20. It is shown that dimensionless concentration rates at the wall has a higher value when the parameters $b$, Sc has high values for $S=0.5$ and $S=1.5$.

\section{Conclusion}

In this work, we have used Lie group method to obtain similarity reductions of nonlinear boundary-layer equations for the two-dimensional MHD steady, laminar flow, and mass transfer of a viscoelastic fluid near a stagnation point; this flow is over a stretching surface with slip velocity; the surface is heated from down by a hot fluid. By determining Lie transformation group under which the given partial differential equations are invariant, we obtained the invariants and the symmetries of these equations. The resulting system of nonlinear ordinary differential equations is solved numerically using the shooting method coupled with RungeKutta scheme. The effects of the viscoelastic parameter $K$, magnetic parameter $M$, slip velocity parameter $a$, convective parameter $\beta$, concentration diffusivity parameter $b$, Prandtl number Pr, Schmidt number Sc, and free-stream velocity 


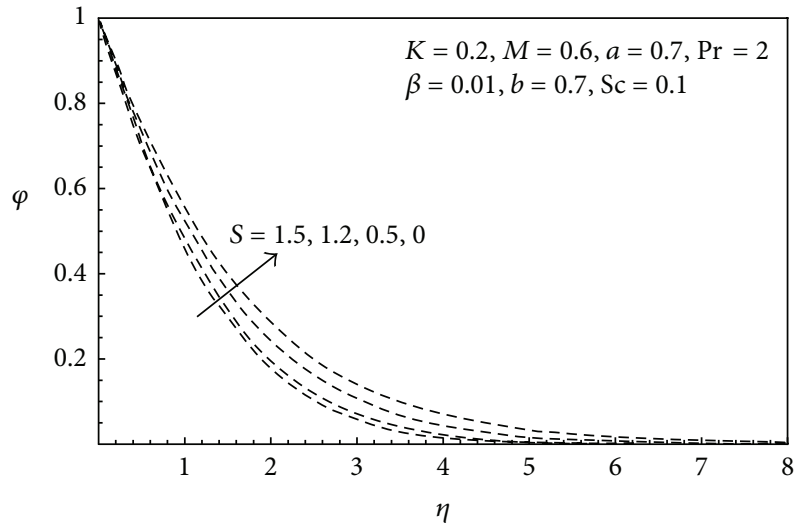

Figure 16: Mass profiles for various values of $S$.

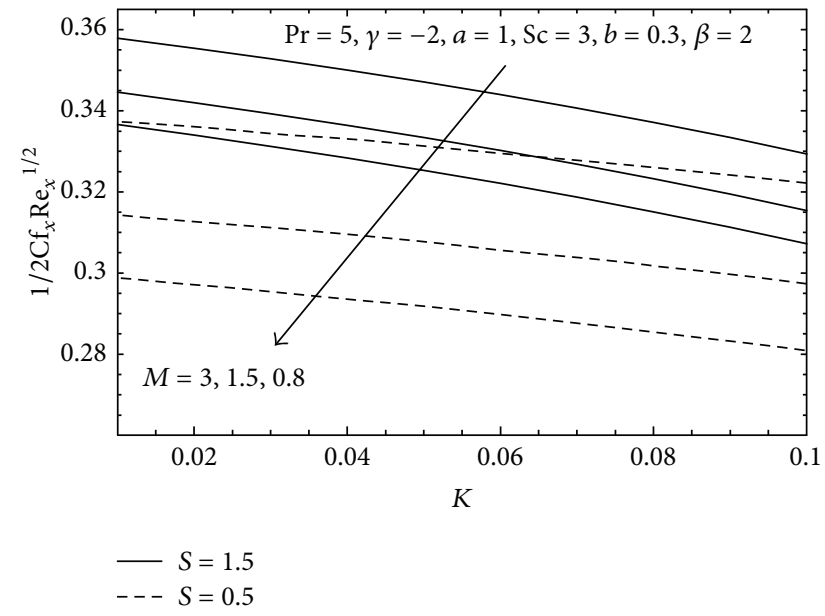

FIgURE 17: Local skin-friction coefficient as a function of $K$ for various values of $M$.

parameter $S$ have been studied. It was found that with the increasing in viscoelastic parameter the velocity decreases near the surface, and the reverse is true away from the surface for $S=1.5$, whereas the velocity increases with an increase in $K$ near the surface, and the reverse is true away from the surface for $S=0.5$. The convective parameter $\beta$ increases the temperature and thicknesses of the boundary layer. A concentration diffusivity parameter $b$ decreases the concentration.

\section{Nomenclature}

a: $\quad$ Slip parameter

$b$ : $\quad$ Concentration diffusivity parameter

$B_{0}$ : Applied magnetic field

$C: \quad$ Species concentration

$C f_{x}$ : Local skin-friction coefficient

$c_{p}: \quad$ Specific heat at constant pressure

$D(C)$ : Variable diffusivity

$D_{m}$ : Constant concentration diffusivity

$f: \quad$ Dimensionless stream function

$h_{f}$ : Heat transfer coefficient

K: $\quad$ Viscoelastic parameter

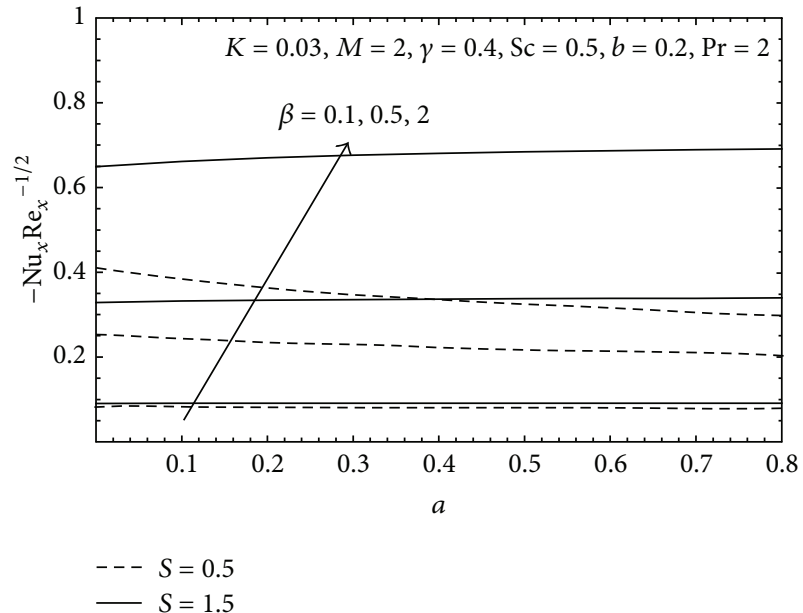

FIGURE 18: Local Nusselt number as a function of $a$ for various values of $\beta$.

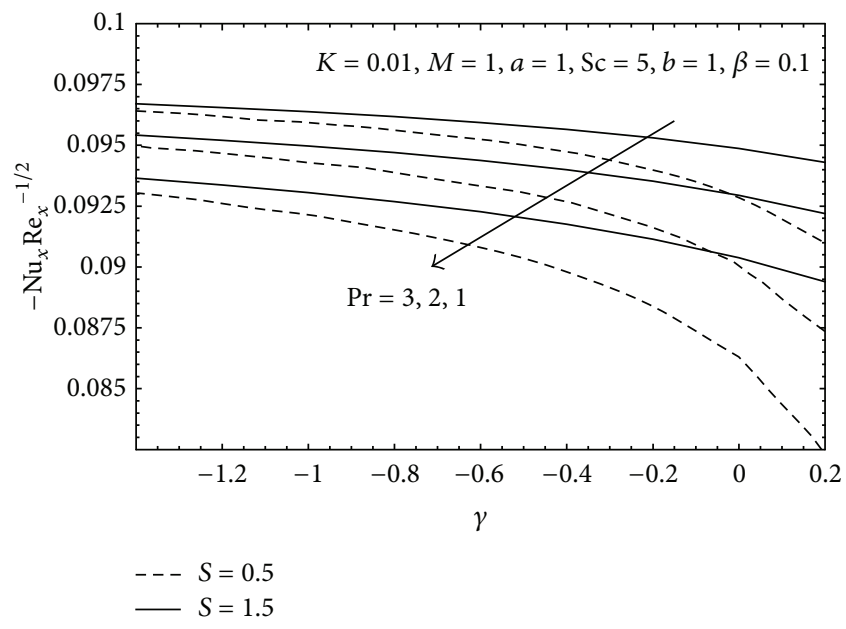

FIGURE 19: Local Nusselt number as a function of $\gamma$ for various values of Pr.

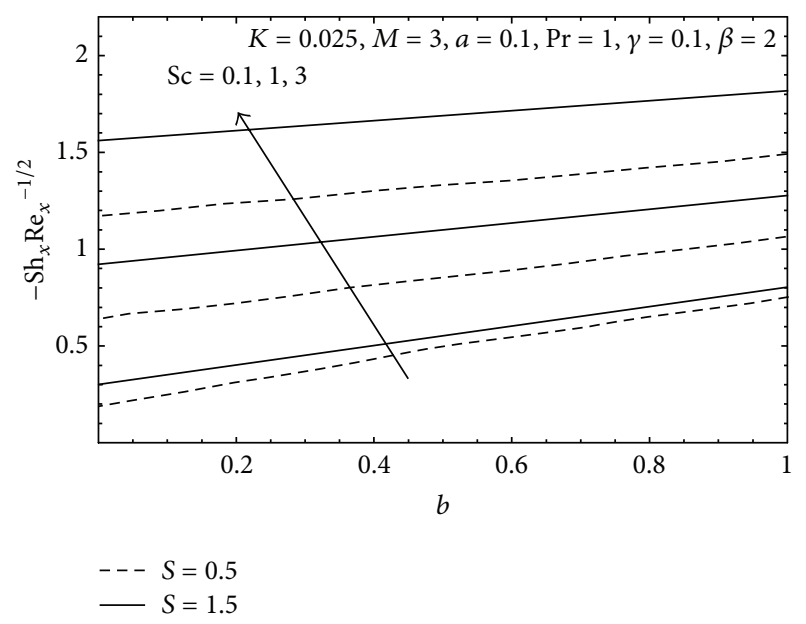

FIGURE 20: Local Sherwood number as a function of $b$ for various values of Sc. 
$K_{0}: \quad$ Kinematic coefficient of viscoelasticity

L: $\quad$ Dimensionless length

M: $\quad$ Magnetic parameter

$\mathrm{Nu}_{x}$ : Local Nusselt number

$N_{1}$ : Slip velocity factor

Pr: $\quad$ Prandtl number

Q: $\quad$ Rate of heat generation/absorption

Re: Reynolds number

S: $\quad$ Ratio between the free-stream velocity and stretch sheet velocity

Sc: Schmidt number

$\mathrm{Sh}_{x}$ : Local Sherwood number

$T: \quad$ Fluid temperature

$T_{f}$ : Hot fluid temperature

$U_{0}$ : Characteristic velocity

$u_{e}$ : Velocity at stagnation point

$u_{w}: \quad$ Stretch sheet velocity

$(u, v)$ : Velocity component along $(x, y)$-axis

$(x, y)$ : Cartesian coordinates.

\section{Greek Symbols}

\author{
$\beta$ : Convective parameter \\ $\kappa$ : Thermal conductivity \\ $\eta$ : Similarity variable \\ $\theta$ : Dimensionless temperature \\ $\varphi$ : Dimensionless concentration \\ $\nu$ : Kinematic viscosity \\ $\rho$ : Density \\ $\psi$ : Stream function \\ $\gamma$ : Heat generation/absorption coefficient.
}

\section{Superscripts}

I: Differentiation with respect to $\eta$.

\section{Subscripts}

$w$ : Wall condition

$\infty$ : Free-stream condition.

\section{References}

[1] K. R. Rajagopal, T. Y. Na, and A. S. Gupta, "Flow of a viscoelastic fluid over a stretching sheet," Rheologica Acta, vol. 23, no. 2, pp. 213-215, 1984.

[2] B. S. Dandapat and A. S. Gupta, "Flow and heat transfer in a viscoelastic fluid over a stretching sheet," International Journal of Non-Linear Mechanics, vol. 24, no. 3, pp. 215-219, 1989.

[3] K. Vajravelu and D. Rollins, "Heat transfer in a viscoelastic fluid over a stretching sheet," Journal of Mathematical Analysis and Applications, vol. 158, no. 1, pp. 241-255, 1991.

[4] D. Kelly, K. Vajravelu, and L. Andrews, "Analysis of heat and mass transfer of a viscoelastic, electrically conducting fluid past a continuous stretching sheet," Nonlinear Analysis: Theory, Methods \& Applications, vol. 36, no. 6, pp. 767-784, 1999.
[5] E. Sanjayanand and S. K. Khan, "On heat and mass transfer in a viscoelastic boundary layer flow over an exponentially stretching sheet," International Journal of Thermal Sciences, vol. 45, no. 8, pp. 819-828, 2006.

[6] R. Cortell, "Toward an understanding of the motion and mass transfer with chemically reactive species for two classes of viscoelastic fluid over a porous stretching sheet," Chemical Engineering and Processing: Process Intensification, vol. 46, no. 10, pp. 982-989, 2007.

[7] M. A. A. Mahmoud, "Chemical reaction and variable viscosity effects on flow and mass transfer of a non-Newtonian viscoelastic fluid past a stretching surface embedded in a porous medium," Meccanica, vol. 45, no. 6, pp. 835-846, 2010.

[8] M. S. Abel, E. Sanjayanand, and M. M. Nandeppanavar, "Viscoelastic MHD flow and heat transfer over a stretching sheet with viscous and ohmic dissipations," Communications in Nonlinear Science and Numerical Simulation, vol. 13, no. 9, pp. 1808-1821, 2008.

[9] A. K. Singh, "Heat source and radiation effects on magnetoconvection flow of a viscoelastic fluid past a stretching sheet: Analysis with Kummer's functions," International Communications in Heat and Mass Transfer, vol. 35, no. 5, pp. 637-642, 2008.

[10] M. S. Abel and N. Mahesha, "Heat transfer in MHD viscoelastic fluid flow over a stretching sheet with variable thermal conductivity, non-uniform heat source and radiation," Applied Mathematical Modelling, vol. 32, no. 10, pp. 1965-1983, 2008.

[11] K. L. Hsiao, "Viscoelastic fluid over a stretching sheet with electromagnetic effects and nonuniform heat source/sink," Mathematical Problems in Engineering, vol. 2010, Article ID 740943, 14 pages, 2010.

[12] C. H. Chen, "On the analytic solution of MHD flow and heat transfer for two types of viscoelastic fluid over a stretching sheet with energy dissipation, internal heat source and thermal radiation," International Journal of Heat and Mass Transfer, vol. 53, no. 19-20, pp. 4264-4273, 2010.

[13] M. M. Nandeppanavar, K. Vajravelu, and M. S. Abel, "Heat transfer in MHD viscoelastic boundary layer flow over a stretching sheet with thermal radiation and non-uniform heat source/sink," Communications in Nonlinear Science and Numerical Simulation, vol. 16, no. 9, pp. 3578-3590, 2011.

[14] C. L. Hii, C. L. Law, and M. Cloke, "Determination of effective diffusivity of cocoa beans using variable diffusivity model," Journal of Applied Sciences, vol. 9, no. 17, pp. 3116-3120, 2009.

[15] E. Azuara, E. Flores, and C. I. Beristain, "Water diffusion and concentration profiles during osmodehydration and storage of apple tissue," Food and Bioprocess Technology, vol. 2, no. 4, pp. 361-367, 2009.

[16] M. A. A. Hamad, J. Md. Uddin, and A. I. MD. Ismail, "Investigation of combined heat and mass transfer by Lie group analysis with variable diffusivity taking into account hydrodynamic slip and thermal convective boundary conditions," International Journal of Heat and Mass Transfer, vol. 55, no. 4, pp. 1355-1362, 2011.

[17] T. R. Mahapatra and A. S. Gupta, "Stagnation-point flow of a viscoelastic fluid towards a stretching surface," International Journal of Non-Linear Mechanics, vol. 39, no. 5, pp. 811-820, 2004.

[18] M. Ayub, H. Zaman, M. Sajid, and T. Hayat, "Analytical solution of stagnation-point flow of a viscoelastic fluid towards a stretching surface," Communications in Nonlinear Science and Numerical Simulation, vol. 13, no. 9, pp. 1822-1835, 2008. 
[19] D. Li, F. Labropulu, and I. Pop, "Mixed convection flow of a viscoelastic fluid near the orthogonal stagnation-point on a vertical surface," International Journal of Thermal Sciences, vol. 50, no. 9, pp. 1698-1705, 2011.

[20] G. W. Bluman and S. Kumei, Symmetries and Differential Equations, vol. 81 of Applied Mathematical Sciences, Springer, New York, NY, USA, 1989.

[21] N. H. Ibragimov, Transformation Groups Applied to Mathematical Physics, Mathematics and Its Applications (Soviet Series), D. Reidel, Dordrecht, The Netherlands, 1985.

[22] P. J. Olver, Applications of Lie Groups to Differential Equations, vol. 107 of Graduate Texts in Mathematics, Springer, New York, NY, USA, 1986.

[23] N. H. Ibragimov, Ed., CRC Handbook of Lie Group Analysis of Differential Equations, Volume I: Symmetries, Exact Solutions and Conservation Laws, CRC Press, Boca Raton, Fla, USA, 1994.

[24] N. H. Ibragimov, Ed., CRC Handbook of Lie Group Analysis of Differential Equations, Volume II: Applications in Engineering and Physical Sciences, CRC Press, Boca Raton, Fla, USA, 1995.

[25] N. H. Ibragimov, Ed., CRC Handbook of Lie Group Analysis of Differential Equations, Volume III: New Trends in Theoretical Developments and Computational Methods, CRC Press, Boca Raton, Fla, USA, 1996.

[26] M. Bhuvaneswari, S. Sivasankaran, and M. Ferdows, "Lie group analysis of natural convection heat and mass transfer in an inclined surface with chemical reaction," Nonlinear Analysis: Hybrid Systems, vol. 3, no. 4, pp. 536-542, 2009.

[27] M. B. Abd-el-Malek and H. S. Hassan, "Symmetry analysis for steady boundary-layer stagnation-point flow of Rivlin-Ericksen fluid of second grade subject to suction," Nonlinear Analysis: Modelling and Control, vol. 15, no. 4, pp. 379-396, 2010.

[28] M. Jalil, S. Asghar, and M. Mushtaq, "Lie group analysis of mixed convection flow with mass transfer over a stretching surface with suction or injection," Mathematical Problems in Engineering, vol. 2010, Article ID 264901, 14 pages, 2010.

[29] M. A. A. Hamad and M. Ferdows, "Similarity solution of boundary layer stagnation-point flow towards a heated porous stretching sheet saturated with a nanofluid with heat absorption/generation and suction/blowing: a Lie group analysis," Communications in Nonlinear Science and Numerical Simulation, vol. 17, no. 1, pp. 132-140, 2012.

[30] P. M. Kishore, V. Rajesh, and S. Vijayakumar Verma, "Viscoelastic buoyancy-driven MHD free convective heat and mass transfer past a vertical cone with thermal radiation and viscous dissipation effects," The International Journal of Applied Mathematics and Mechanics, vol. 6, no. 15, pp. 67-87, 2010. 


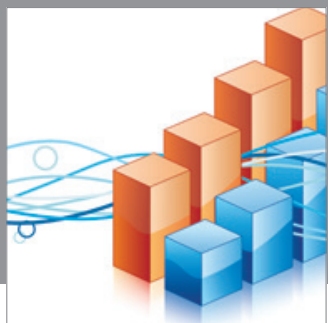

Advances in

Operations Research

mansans

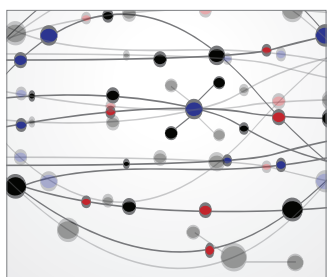

The Scientific World Journal
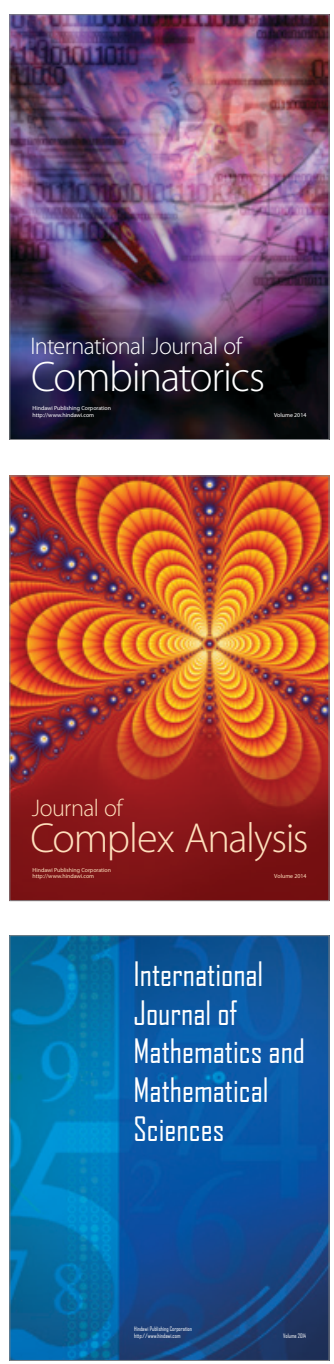
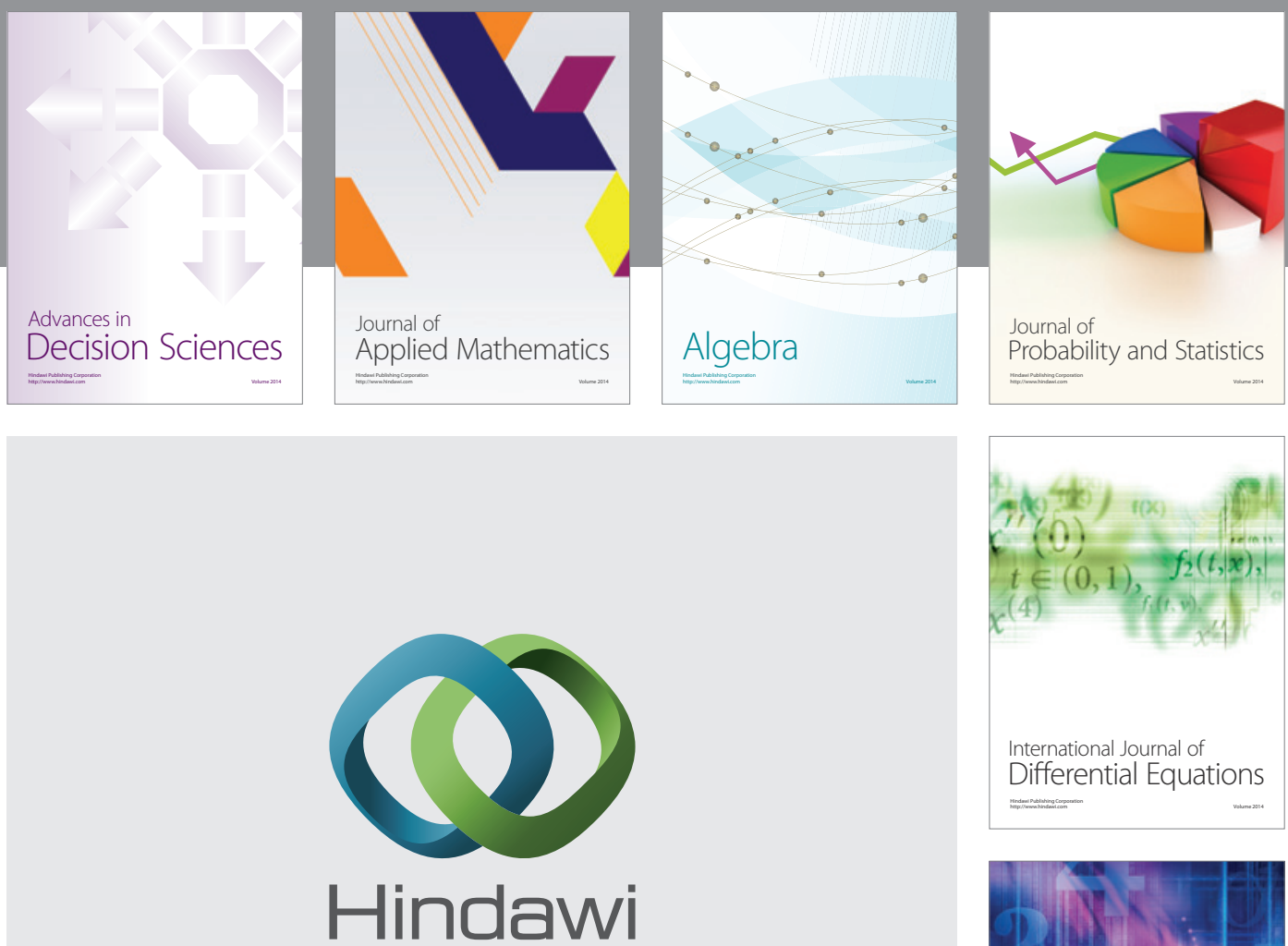

Submit your manuscripts at http://www.hindawi.com
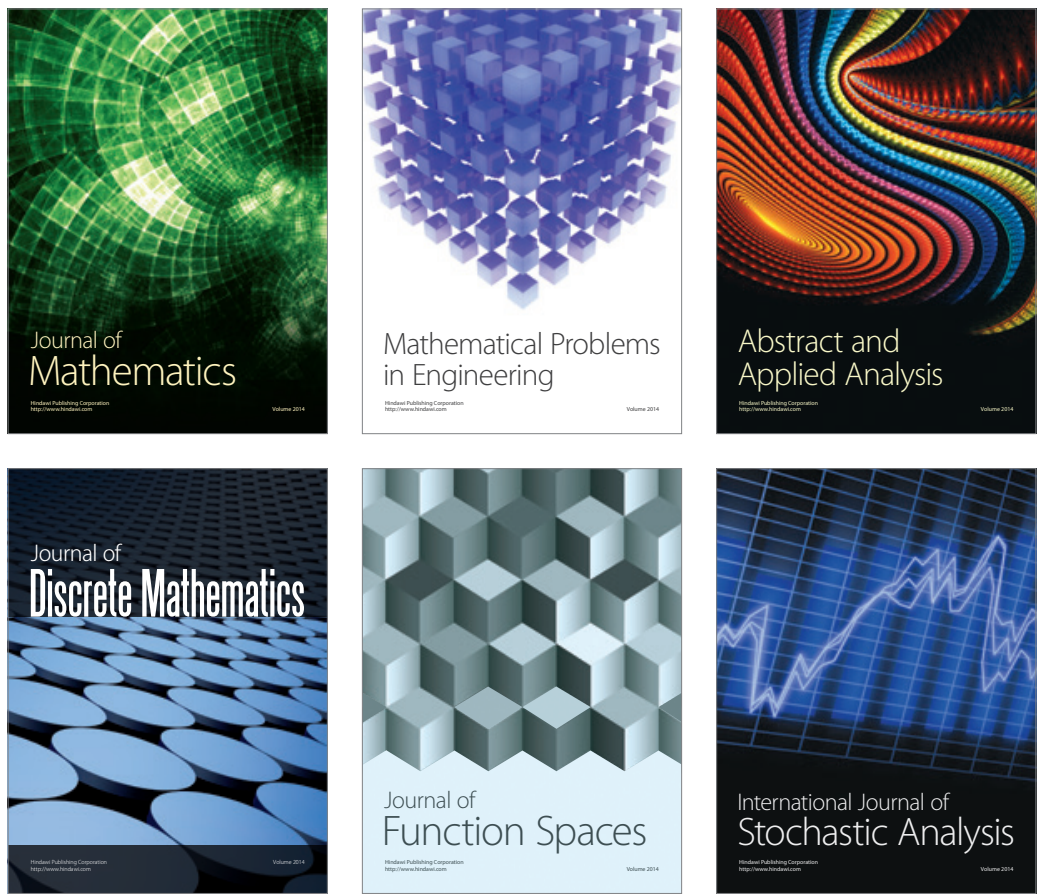

Journal of

Function Spaces

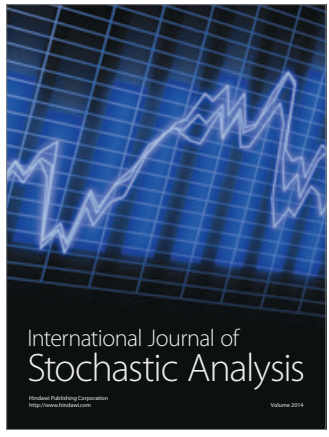

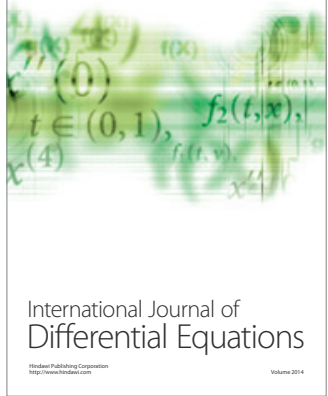
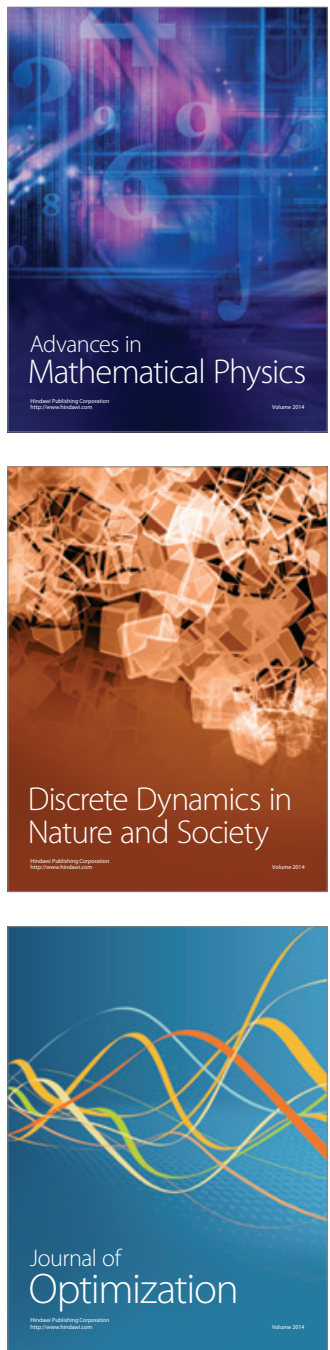